Ngoài thành phần công thức, độ tăng trọng của lớp bao tan trong ruột là một trong những yếu tố quan trọng nhất giúp hạt kháng lại môi trường acid. Độ tăng trọng lớp bao càng tăng, khả năng kháng acid càng tốt nên độ giải phóng hoạt chát hoạt chất trong môi trường acid $\mathrm{HCl}$ $0,1 \mathrm{~N}$ giảm. Tuy nhiên khả năng giải phóng hoạt chất trong môi trường đệm $\mathrm{pH}$ 6,8 cũng giảm theo. Do đó, độ dày lớp bao tan trong ruột 30\% là đạt yêu cầu.

\section{KẾT LUÂNN}

Đã bào chế được viên nang chứa esomeprazol $20 \mathrm{mg}$ dang hạt bao tan trong ruột đạt các tiêu chuẩn kiểm nghiệm của USP43.
TÀI LIẸU THAM KHẢO

1. Chemical Medicines Monographs 3 Expert Committee (2016), "Esomeprazole Magnesium Delayed-Release Capsules", pp.1-4.

2. Shu-Ling Kan et al (2014), "Preparation and in vitro/in vivo evaluation of esomeprazole magnesium modified release", Informa healthcare,pp.1-8.

3. Singh Deep Hussan et al (2012), "A review on recent advances of enteric coating", IOSR Journal of Pharmacy, vol 2, pp.05-11.

4. USP43-NF38 (2019), The United States Pharmacopedial Convention.

5. Yongmei Xie, Ping Xie (2008), "Preparation of esomeprazole zinc solid dispersion and study on its pharmacokinetics", pp.53-57.

\title{
SỐ LƯợNG ỐNG TỦY CHÂN RĂNG CỦA RĂNG CỐI LỚN THỨ NHẤT HÀM DƯỚI TRÊN CONEBEAM CT TRONG ĐIỀU TRI NHA KHOA
}

\section{TÓM TẮT}

Mục tiêu: Đây là nghiên cứu khảo sát trên phim ConeBeam $\mathrm{CT}$ nhằm xác định số ống tủy của răng cối lớn (RCL) thứ nhất hàm dưới ở người Việt Nam. Đối tương và phương pháp: Nghiên cứu được thực hiện trên 166 bệnh nhân chụp phim CBCT theo chỉ định của bác sĩ tai Trung tâm CT nha khoa Nguyễn Trãi, Thành Phố Hồ Chí Minh, trong thời gian nghiên cứu từ tháng 10/2015 đến tháng 6/2016. Phim CBCT được chụp bằng máy chụp phim Picasso Trio (Ewoo Vatech, Korea) với các điều kiện và tư thế chuẩn của bệnh nhân cho chụp phim. Hình ảnh $\mathrm{CB} C \mathrm{~N}$ thu thập từ trung tâm CT đạt tiêu chuẩn chọn mẫu được quạn sát trên máy tính màn hình phẳng 14 inches, độ phân giải 1366 x 768 pixel với phần mềm EzImplant CD viewer. Ghi nhận vị trí răng (răng 36 và răng 46), khảo sát số lượng ống tủy của răng cối lớn thứ nhất hàm dưới trển hình ảnh $\mathrm{CBCT}$ : trong mặt phẳng ngang (Axial), di chuyển các lát cắt trên thiết diện ngang của ống tủy từ sàn tủy đến chóp. Quan sát theo thiết diện ngang ở những mức sau: miệng ống tủy, phần ba giữa chân răng, phần ba chóp chân răng. Quan sát ống tủy của từng chân răng của răng cối lớn thứ nhất hàm dưới theo ba măt phẳng. Xác đinh số lượng ống tủy. Kết quả: Tỉ lệ RCL thứ nhất hàm dưới có hai ông tủy, ba ống tủy, bốn ống tủy, lần lượt là $4,5 \%, 66,8 \%$ và $28,9 \%$. Sự phân bố này khác biệt không có ý nghĩa theo giới tính và theo vị trí. Kết luận: Tî lệ RCL thứ nhất hàm dưới trên CONEBEAM CTं có ba ống tủy

${ }^{1}$ Đại học Y Dước TP.HCM

Chịu trách nhiệm chính: Huỳnh Kim Khang

Email: kimkhanghuynh@yahoo.com

Ngày nhận bài: 8/3/2021

Ngày phản biện khoa học: 4/4/2021

Ngày duyệt bài: 2/5/2021
Huỳnh Kim Khang ${ }^{1}$, Phạm Văn Khoa ${ }^{1}$

chiếm đa số

Tư khóa: Ống tủy chân răng, răng cối lớn thứ nhất hàm dưới, ConeBeam CT.

Viết tắt: RCL1: răng cối lớn thứ nhất; $\mathrm{CBCT}$ : ConeBeam CT

\section{SUMMARY}

THE NUMBER OF THE ROOT CANALS OF THE FIRST LOWER MOLARS ON CONEBEAM CT IN DENTAL TREATMENT

Objectives: The aim of the study is to determine the number of the root canals of the first lower molars in Vietnamese on ConeBeam CT. Subjects and methods: The study was conducted on 166 patients who had exposured using CBCT indicated by dentists in Nguyen Trai Dental CT Central, HoChiMinh City, from October 2015 to June 2016. The CBCT digital images were captures using Picasso Trio (Ewoo Vatech, Korea) with the standard conditions and postures of patients. CBCT digital images were displayed on the 14 inches flat monitor, at 1366 × 768 pixel resolution with EzImplant CD viewer software. The positions of the first lower molars were recorded. The number of root canals of the first lower molars was examined by moving cross-sectional slices from the pulpal floor to the apex. The orifices, middle thirds, apical thirds of the canals of the first lower molar was observed and the root canals of each root of the first lower molars were observed in three planes Results: The prevalences of two, three, four root canals of the first lower molars were $4.5 \%$, $66.8 \%$ and $28.9 \%$ respectively. There were not significant differences about sex and positions. Conclusion:The prevalences of three root canals of the first lower molars accounts for the largest portion.

Key words: Root canals, first lower molar, ConeBeam CT. 


\section{I. ĐẶT VẤN ĐỀ}

Trong bộ răng con người, răng cối lớn thứ nhất hàm dưới là một trong những răng vĩnh viễn đâu tiên mọc lên trong miệng, vào khoảng sáu tuổi, đánh dấu sự khởi đầu của bộ răng hỗn hợp. Răng cối lớn thứ nhất hàm dưới mang đặc điểm cơ bản đặc trưng của các răng cối lớn, có vai trò quan trọng trong việc nhai nghiền thức ăn và giữ kích thước tâng dưới mặt.

Răng có tỉ lệ sâu mất trám cao nhất trên lâm sàng chính là rắng cối lớn thứ nhất hàm dưới, kể cả ở lứa tuổi còn trẻ. Do đó, những hiểu biết về hình thái chân răng, số lượng và vị trí ống tủy là rất quan trọng và cần thiết trong quá trình điều trị nha khoa như điều tri nôi nha, phẫu thuật cắt chóp, nhổ răng. Răng cối lớn thứ nhất hàm dưới có hình thái chân răng và ống tủy khá phức tạp, đa số có hai chân răng và ba ống tủy [1]. Tuy nhiên, ở các chủng tộc Mongoloid, tỉ lệ răng cối lớn thứ nhất hàm dưới có ba chân (thêm một chân ở phía xa trong) tương đối cao, chiếm khoảng $20 \%$, vì đây là răng vĩnh viễn mọc đầu tiên trên cung hàm và có hệ thống ống tủy phức tạp và cũng là răng có chức năng ăn nhai quan trọng cần được bảo tồn nhất. Số lượng ống tủy thay đổi khi răng cối lớn thứ nhất hàm dưới có ba chân. Do đó, việc nghiên cứu về số lượng và vị trí ống tủy của răng cối lớn thứ nhất hàm dưới sẽ giúp các nhà lâm sàng có thêm cơ sở khi điều trị nội nha răng này và tránh được sai lầm bỏ sót ống tủy, một nguyên nhân thường gặp gây thất bại trong điều trị nội nha.

Nhằm giúp các nhà lâm sàng đưa ra kế hoạch điều trị tối ưu nhất cũng như dự đoán được tiên lương trước khi tiến hành điều tri phục hồi và bảo tồn, nhiều nghiên cứu trên thế giới đã tập trung khảo sát những đặc điểm giải phẫu vùng răng cối lớn thứ nhất hàm dưới về hình thái và số lượng chân răng với mong muốn tạo ra một bộ cở sở dữ liệu về vùng giải phẫu quan trọng này. Hiện nay, đây là công cụ tốt nhất để khảo sát mô cứng vùng răng hàm mặt, theo ba chiều trong không gian với ưu điểm cho hình ảnh rõ nét, giảm thiểu độ biến dạng và kỹ thuật hầu như là không xâm lấn. Mục tiêu của nghiển cứu là nhằm xác định số lượng ống tủy răng cối lớn thứ nhất hàm dưới ở người Việt Nam khảo sát trên phim CBCT.

\section{II. ĐỐI TƯợNG VÀ PHƯƠNG PHÁP NGHIÊN CỨU}

2.1. Thiết kế nghiên cứu: Nghiên cứu cắt ngang mô tả

2.2. Mẫu nghiên cứu: là các phim $\mathrm{CBCT}$ xương hàm dưới của các cá thể thỏa điều kiện chọn mẫu được chụp theo chỉ định của bác sĩ tại Trung tâm CTं nha khoa Nguyển Trãi - địa chỉ 132 An Bình - Quận 5 - thành phố Hồ Chí Minh, trong thời gian nghiên cứu từ tháng 10/2015 đến tháng 6/2016. Dựa vào tỉ lệ răng cối lớn thứ nhất hàm dưới có ba chân ở người Thái Lan (nghiên cứu của Gulabivala và c.s. (2002) [5]) p $=0,127$, trong nghiên cứu này tính được cỡ mẫu tương ứng là $n=166$. Công thức tính cỡ mẫu $n=$ $\left[Z^{2}{ }_{1-a / 2} p(1-p) / d^{2}\right]$ (trong đó $a=0,02$ : xác suất sai lâm loại I; $Z_{1-a / 2}=2,32$ : trị số phân phối chuẩn; $\mathrm{d}=0,06$ : độ chính xác mong muốn). Hình ảnh $\mathrm{CBCT}$ xương hàm dưới của người Việt Nam có đủ hai răng cối lớn thứ nhất hàm dưới (răng 36 và răng 46). Phim CBCT được chụp bằng máy chụp phim Picasso Trio (Ewoo Vatech, Korea) với các điều kiên và tư thế chuẩn của bênh nhân cho chụp phim (chiều dày mỗi lát cắt $0,1 \mathrm{~mm}$; FOV: $8 \times 5 \mathrm{~cm}$; thời gian chụp: 15 giây; thời gian dựng ảnh 29 giây). Răng cối lớn thứ nhất hàm dưới thỏa điều kiện: răng phát triển đầy đủ và đã đóng chóp. Các răng khảo sát không có bất thường về vị trí, không có tiêu ngót chân răng, bệnh lý nha chu, nhiễm trùng chóp ảnh hưởng đến việc đánh giá vách xương, ống thần kinh răng dưới; răng không có điều trị nội nha, thân và chân răng không bị các tổn thương (sâu răng, mòn răng, nứt) hay miếng trám lớn ảnh hưởng đến hốc tủy, có đầy đủ thông tin về năm sinh, giới tính, ngày chụp; phim đạt chuẩn, hình ảnh rõ nét, độ sáng đủ, độ tương phản rõ.

Hình ảnh CBCT thu thâp từ trung tâm CT đạt tiêu chuẩn chọn mẫu được quan sát trên máy tính màn hình phẳng 14 inch, độ phân giải 1366 $x 768$ pixel với phần mềm EzImplant $C D$ viewer. Quan sát trên phim và ghi nhận kết quả. Ghi nhận mã số phim, giới tính, tuổi, ngày chụp, tên bệnh nhân (viết tắt) vào phiếu thu thập. Khi tiến hành đo phần thông tin của bệnh nhân trên phim và trên phiếu thu thấp kết quả được che đi. Phim cần đo được chuyển về chế độ xem gốc ban đâu (thao tác Reset all), với độ phóng đại 1,5 lần. Khảo sát các đặc điểm giải phẫu hệ thống ống tủy của răng cối lớn thứ nhất hàm dưới trên hình ảnh $\mathrm{CBCT}$ : trong mặt phẳng ngang (Axial), di chuyển các lát cắt trên thiết diện ngang của ống tủy từ sàn tủy đến chóp. Quan sát theo thiết diện ngang ở những mức sau: miệng ống tủy, phần ba giữa chân răng, phần ba chóp chân răng. Quan sát ống tủy của từng chân răng của răng cối lớn thứ nhất hàm dưới theo ba mặt phẳng. Xác định số lượng ống tủy của răng cối lớn thứ nhất hàm dưới.

2.3. Vấn đề y đức. Nghiên cứu của chúng 
tôi không vi pham y đức vì: phim CBCT hiên được xem là phương tiện chẩn đoán tốt nhất, với hình ảnh chi tiết có thể khắc phục nhược điểm của phim hai chiều và được sử dụng rộng rãi trong chẩn đoán; nghiên cứu chỉ thu thâp phim của bệnh nhân có chỉ định chụp CBCT tại phòng CT Nguyễn Trãi theo chỉ định của bác sĩ điêu trị; các thông tin của $B N$ được bảo mật hoàn toàn và chỉ sử dụng cho mục đích nghiển cứu; nghiên cứu được thông qua bởi Hội đồng đạo đức trong nghiên cứu y sinh học ĐHYD Tp. Hồ Chí Minh (tháng 10/2015).

\section{KẾT QUẢ NGHIÊN CỨU}

3.1. Đặc điểm mẫu nghiên cứu. Mẫu nghiên cứu gồm phim CBCT của 166 người, trong đó nam chiếm $56,6 \%$ và nữ chiếm $43,4 \%$ (Bảng 1). Xét theo nhóm tuổi có 83 đối tượng từ 30-50tuổi, cao hơn gấp đôi so với đối tượng dưới 30 tuổi (41 người) và trên 50 tuổi (42 người).

Bảng 1. Đặc điểm mẫu nghiên cứu.

\begin{tabular}{|c|c|c|c|}
\hline \multirow{2}{*}{ Nhóm tuổi } & \multicolumn{3}{|c|}{ Mâu nghiên cứu (n = 166) } \\
\cline { 2 - 4 } & $\begin{array}{c}\mathbf{N a m} \\
\mathbf{n}(\%)\end{array}$ & $\begin{array}{c}\mathbf{N} \text { ữ } \\
\mathbf{n}(\mathbf{\%})\end{array}$ & $\begin{array}{c}\text { Tống } \\
\mathbf{n}\end{array}$ \\
\hline Từ 18- dưới 30 & $16(17)$ & $25(34,7)$ & 41 \\
\hline Tữ $30-50$ & $42(44,7)$ & $41(56,9)$ & 83 \\
\hline Trên 50 & $36(38,3)$ & $6(8,3)$ & 42 \\
\hline Toàn mâu & 94 & 72 & 166 \\
\hline
\end{tabular}

Mỗi đối tượng trong mẫu nghiên cứu được khảo sát 2 răng cối lớn thứ nhất hàm dưới gồm răng 36 và răng 46, tổng cộng có 332 răng được nghiên cứu.

Bảng 3. Tần suất và tỉ lệ số chân răng và số ống tủy của răng cối lớn thứ nhất hàm dưới theo theo giới tính và theo vi trí.

\begin{tabular}{|c|c|c|c|c|c|c|c|}
\hline & \multicolumn{2}{|c|}{ Trái } & & \multicolumn{2}{|c|}{\begin{tabular}{|c|} 
Phải \\
\end{tabular}} & \multirow[b]{2}{*}{ Số răng n(\%) } & \multirow{2}{*}{\begin{tabular}{|c|} 
Tống \\
Số răng $\mathbf{n}(\%)$ \\
\end{tabular}} \\
\hline & $\operatorname{Nam}(\mathbf{n})$ & $\mathbf{N} \tilde{u}(\mathbf{n})$ & Số răng n(\%) & $\operatorname{Nam(n)}$ & $\mathbf{N u ̛ ̃}(\mathbf{n})$ & & \\
\hline \multicolumn{8}{|c|}{ Răng cối lớn } \\
\hline 2 chân & 84 & 66 & $150(90,4)$ & 78 & 63 & $141(84,9)$ & $291(87,7)$ \\
\hline 3 chân & 10 & 6 & $16(9,6)$ & 16 & 9 & $25(15,1)$ & $41(12,3)$ \\
\hline \multicolumn{8}{|c|}{ Số ống tủy } \\
\hline 2 ống tủy & 1 & 8 & $9(5,4)$ & 0 & 6 & $6(3,6)$ & $15(4,5)$ \\
\hline 3 ống tủy & 69 & 44 & $113(68,1)$ & 66 & 42 & $108(65,1)$ & $221(66,6)$ \\
\hline 4 ống tủy & 24 & 20 & $44(26,5)$ & 28 & 24 & $52(31,3)$ & $96(28,9)$ \\
\hline \multicolumn{8}{|c|}{ RCL1 HD có 4 ống tủy } \\
\hline 2 chân & 15 & 14 & $29(65,9)$ & 12 & 16 & $28(53,8)$ & $57(59,4)$ \\
\hline 3 chân & 9 & 6 & $15(34,1)$ & 16 & 8 & $24(46,2)$ & $39(40,6)$ \\
\hline
\end{tabular}

Trong các răng cối lớn thứ nhất hàm dưới có bốn ống tủy thì có đến 40,6\% (39/96) là răng cối lớn thứ nhất hàm dưới có ba chân.

\section{BÀN LUÂN}

Nghiên cứu được thực hiên trên dữ liêu phim CBCT của 166 người trong kho phim CBCT lưu trữ tại trung tâm CT Nguyễn Trãi. Trong 166 người đưa vào nghiên cứu, có 94 nam và 72 nũ̃, tỉ lệ nam : nữ tương đương 3:2. Xét sự phân bố
3.2. Đặc điểm sự phân bố của răng cối lớn thứ nhất hàm dưới theo số lượng chân răng và số lượng ống tủy. Tỉ lệ phân bố răng cối lớn thứ nhẩt hàm dưới theo số lượng chân răng và số lượng ống tủy được liệt kê trong bảng 2 và bảng 3 . Tần suất các răng cối lớn thứ nhất hàm dưới có hai ống tủy, ba ống tủy, bốn ống tủy, lần lượt là $4,5 \%, 66,6 \%$ và $28,9 \%$. Sự phân bố này theo giới tính và theo vị trí khác biệt không có ý nghĩa thống kê $(p=0,56 ; p=0,97)$.

ở các răng cối lớn thứ nhất hàm dưới có hai chân, tỉ lệ răng có hai, ba, bốn ống tủy lần lượt là 4,5\%,66\%, 17,2\%. Hầu như tất cả các răng cối lớn thứ nhất hàm dưới có ba chân đều có bốn ống tủy, chỉ có 2 răng là có ba ống tủy.

Bảng 2. Sự phân bố tần suất số chân răng và số ống tủy của răng cối lớn thứ nhất hàm dưới theo theo giới tính.

\begin{tabular}{|c|c|c|c|}
\hline & $\begin{array}{c}\text { Nam } \\
(\mathbf{n = 9 4 )} \\
\mathbf{n ( \% )}\end{array}$ & $\begin{array}{c}\mathbf{N} \mathbf{\text { N }} \\
(\mathbf{n}=\mathbf{7 2}) \\
\mathbf{n ( \% )}\end{array}$ & $\begin{array}{c}\text { Tống (n } \\
\mathbf{1 6 6 )} \\
\mathbf{n}(\mathbf{\%})\end{array}$ \\
\hline Tổng số răng & $188(56,6)$ & $144(43,4)$ & $332(100)$ \\
\hline $\begin{array}{c}\text { RCL1 HD } \\
\text { hai chân }\end{array}$ & $162(48,8)$ & $129(38,9)$ & $291(87,7)$ \\
\hline 2 ống tủy & $1(0,3)$ & $14(4,2)$ & $15(4,5)$ \\
\hline 3 ống tủy & $134(40,4)$ & $85(25,6)$ & $219(66,0)$ \\
\hline 4 ống tủy & $27(8,1)$ & $30(9,1)$ & $57(17,2)$ \\
\hline $\begin{array}{c}\text { RCL1 HD } \\
\text { ba chân }\end{array}$ & $26(7,8)$ & $15(4,5)$ & $41(12,3)$ \\
\hline 3 ống tưy & $1(0,3)$ & $1(0,3)$ & $2(0,6)$ \\
\hline 4 ống tủy & $25(7,5)$ & $14(4,2)$ & $39(11,7)$ \\
\hline
\end{tabular}

theo tuổi, $50 \%$ số cá thể trong mẫu nghiên cứu thuộc nhóm tuổi từ 30 đến 50 . Các cá thể còn lại phân bố khá đồng đều vào hai nhóm tuổi còn lại (41 người dưới 30 tuổi và 42 người trên 50 tuổi). Sự phân bố không đều do tiêu chuẩn chọn mẫu yểu câuu bệnh nhân có nguyên vẹn hai răng cối 
lớn thứ nhất hàm dưới, không có phục hồi, miếng trám, điều trị tủy và không có bệnh lý nha chu nghiêm trọng trong khi đó răng cối lớn nhất hàm dưới lại là răng có tỉ lệ sâu mất trám cao nhất kể cả các lứa tuổi. Sư không tương đồng về giới tính và tuổi của mấu nghiên cứu làm cho việc so sánh giữa các nhóm không thuận lợi.

Việc chia mẫu nghiên cứu thành ba nhóm tuổi như trên là phù hợp với từng giai đoạn phát triển hệ xương của cơ thể và do đó phù hợp để khảo sát bề dày vách xương và khoảng cách từ chóp răng đến ống răng dưới của các cá thể.

Sự xuất hiện của răng cối lớn thứ nhất hàm dưới có ba chân được ghi nhận trong nhiều nghiên cứu với răng sau khi nhổ hoặc phim quanh chóp. Tuy nhiên, răng cối lớn thứ nhất hàm dưới có thể bị gãy chóp trong quá trình nhổ răng, hình ảnh chân trong xa của răng cối lớn thứ nhất hàm dưới trên phim quanh chóp có thể bị chồng và không rõ ràng. Do đó, phương pháp phân tích dữ liẹu trên hình ảnh cắt lớp điện toán nha khoa CBCT với ưu điểm cung cấp thông tin theo ba chiều trong không gian, hình ảnh rõ nét, chính xác, cung cấp thông tin toàn diện về hình thái, số lượng, vị trí chân răng của răng cối lớn thứ nhất hàm dưới.

Tỉ lệ răng cối lớn thứ nhất hàm dưới có hai ống tủy, ba ống tủy, bốn ống tủy, lần lượt là $4,5 \%, 66,8 \%$ và $28,9 \%$. Sự phân bố này khác biệt không có ý nghĩa theo giới tính $(p=0,56)$ và theo vị trí $(p=0,97)$. Kết quả cho thấy răng cối lớn thứ nhất hàm dưới có ba ống tủy và răng cối lớn thứ nhất hàm dưới bốn ống tủy chiếm đa số, trong đó tỉ lệ răng cối lớn thứ nhất hàm dưới ba ống tủy là cao nhất. Kết quả của Huang CC và c.s. (2010) [7] ở người Đài Loan với tỉ lệ răng có hai ống tủy, ba ống tủy, bốn ống tủy lần lượt là $3,4 \%, 56,1 \%, 40,5 \%$. Tương tự, nghiên cứu về số lượng ống tủy răng cối lớn thứ nhất hàm dưới của Yew và c.s. (1993) [8] ở người Đài Loan cho thấy tỉ lệ răng có hai ống tủy, ba ống tủy, bốn ống tủy lần lượt là $6 \%, 62,5 \%, 31,5 \%$.

Ở các RCL thứ nhất hàm dưới có hai chân, tỉ lệ răng có hai ống tủy, ba ống tủy, bốn ống tủy lẩn lướt là $4,5 \%, 66 \%, 17,2 \%$. Ơ các RCL thứ nhất hàm dưới có ba chân, tỉ lệ răng có ba ống tủy, bốn ống tủy lần lượt là $0,6 \%, 11,7 \%$. Trong các răng cối lớn thứ nhất hàm dưới có bốn ống tủy thì có đến 40,6\% (39/96) là RCL thứ nhất hàm dưới có ba chân. Hâuu như tất cả các RCL thứ nhất hàm dưới có ba chân đều có bốn ống tủy, chỉ có 2 răng là có ba ống tủy. Kết quả này tương tư với kết quả trong nghiên cứu Yew và c.s. (1993) [8] trên người Đài Loan cho thấy trong các RCL thứ nhất hàm dưới có bốn ống tủy thì tî lệ RCL thứ nhất hàm dưới ba chân chiếm xấp xỉ 1/2 (62,5\% - 68,3\%).

Gần một nửa $(40,6 \%(39 / 96)$ số $\mathrm{RCL}$ thứ nhất hàm dưới có bốn ống tủy là $49,23 \%$ trong đó $\mathrm{RCL}$ thứ nhất hàm dưới có hai chân và bốn ống tủy là $49,43 \%$ và $R C L$ thứ nhất hàm dưới có ba chân là 50,57\% (475/961), (486/961).

Kỹ thuật chụp phim quanh chóp thông thường chỉ cung cấp hình ảnh hai chiều và phim bị nhiểu nếu răng kế cận có mão răng, miếng trám, đặt chốt hoạc cắm implant. Vì vậy phim $\mathrm{CBCT}$ có thể được chỉ định trong trường hợp tìm thây bất thường trên phim quanh chóp hoặc nhà lâm sàng nghi ngờ hệ thống ống tủy phức tạp hơn bình thường. Uu điểm của CBCT là không xâm lấn, cho hình ảnh ba chiều, quan sát được giải phẫu bên trong và bên ngoài của răng.

Trong nghiên cứu chúng tôi, số lượng chân răng và số lượng ống tủy đều có thể nhìn thấy khá rõ ràng trên các mặt phẳng ngang (Axial). Cả ba mặt phẳng trong CBCT là công cụ hữu ích để nghiền cứu giải phẫu hệ thống ống tủy mà không cần can thiệp đến răng.

\section{KẾT LUẬN}

Tỉ lệ răng cối lớn thứ nhất hàm dưới trên CONEBEAM CT có ba ống tủy chiếm đa số

\section{TÀI LIỆ THAM KHẢO}

1. de Pablo O. V., Estevez R., Peix Sanchez M., et al. (2010), "Root anatomy and canal configuration of the permanent mandibular first molar: a systematic review". J Endod, 36(12), 1919-1931.

2. Chen Y. C., Lee Y. Y., Pai S. F., et al. (2009), "The morphologic characteristics of the distolingual roots of mandibular first molars in a Taiwanese population". J Endod, 35(5), 643-645.

3. Curzon M. E. ,Curzon J. A. (1971), "Threerooted mandibular molars in the Keewatin Eskimo". J Can Dent Assoc (Tor), 37(2), 71-72.

4. de Souza-Freitas J. A., Lopes E. S. ,CasatiAlvares L. (1971), "Anatomic variations of lower first permanent molar roots in two ethnic groups". Oral Surg Oral Med Oral Pathol, 31(2), 274-278.

5. Gulabivala K., Opasanon A., Ng Y. L., et al. (2002), "Root and canal morphology of Thai mandibular molars". Int Endod J, 35(1), 56-62.

6. Serene T. P. Spolsky V. W. (1981), "Frequency of endodontic therapy in a dental school setting". J Endod, 7(8), 385-387.

7. Huang C. C., Chang Y. C., Chuang M. $C_{\text {., }}$ et al. (2010), "Evaluation of root and canal systems of mandibular first molars in Taiwanese individuals using cone-beam computed tomography". J Formos Med Assoc, 109(4), 303-308.

8. Yew S. C. ,Chan K. (1993), "A retrospective study of endodontically treated mandibular first molars in a Chinese population". J Endod, 19(9), 471-473. 